\title{
The cost of schizophrenia in Japan
}

This article was published in the following Dove Press journal:

Neuropsychiatric Disease and Treatment

29 May 2013

Number of times this article has been viewed

\author{
Mitsuhiro Sado' \\ Ataru Inagaki ${ }^{2}$ \\ Akihiro Koreki ${ }^{1}$ \\ Martin Knapp ${ }^{3}$ \\ Lee Andrew Kissane ${ }^{4}$ \\ Masaru Mimura' \\ Kimio Yoshimura ${ }^{4}$ \\ 'Department of Neuropsychiatry, Keio \\ University School of Medicine, ${ }^{2}$ Center \\ for Clinical Psychopharmacology, \\ Institute of Neuropsychiatry, Tokyo, \\ Japan; ${ }^{3}$ Department of Social Policy, \\ London School of Economics and \\ Political Science, London, UK; \\ ${ }^{4}$ Department of Health Policy and \\ Management, Keio University School \\ of Medicine, Tokyo, Japan
}

Correspondence: Mitsuhiro Sado Department of Neuropsychiatry, Keio University School of Medicine, Shinanomachi 35, Shinjuku-ku, Tokyo, 160-8582, Japan

Tel +8 I 33353 I2II ext 62453

Fax +81353790187

Email mitsusado@nifty.com
Introduction: Schizophrenia is a disorder that produces considerable burdens due to its often relapsing/remitting or chronic longitudinal course. This burden is felt not only by patients themselves, but also by their families and health care systems. Although the societal burden caused by this disorder has been evaluated in several countries, the magnitude of the societal cost of schizophrenia in Japan has never been estimated. The aim of this study is to clarify the societal burden of schizophrenia by estimating the cost of schizophrenia in Japan in 2008.

Methods: A human capital approach was adopted to estimate the cost of schizophrenia. The total cost of schizophrenia was calculated as the sum of the direct, morbidity, and mortality costs. Schizophrenia was defined as disorders coded as F20.0-F20.9 according to the International Classification of Diseases-10. The data required to estimate the total cost was collected from publicly available statistics or previously reported studies.

Results: The total cost of schizophrenia in Japan in 2008 was JPY 2.77 trillion (USD 23.8 billion). While the direct cost was JPY 0.770 trillion (USD 6.59 billion), the morbidity and mortality costs were JPY 1.85 trillion (USD 15.8 billion) and JPY 0.155 trillion (USD 1.33 billion), respectively.

Conclusion: The societal burden caused by schizophrenia is tremendous in Japan, similar to that in other developed countries where published data exist. Compared with other disorders, such as depression or anxiety disorders, the direct cost accounted for a relatively high proportion of the total cost. Furthermore, absolute costs arising from unemployment were larger, while the prevalence rate was smaller, than the corresponding results for depression or anxiety in Japan.

Keywords: cost of illness, schizophrenia, societal burden, cost analysis, societal cost

\section{Introduction}

Schizophrenia causes a considerable burden not only for patients themselves, but also for families who must provide care and for social care systems. Several reasons have been proposed to explain the magnitude of the societal cost of this disorder, including the high probability of disease relapse and the high incidence of chronic features According to a report by Crown et al, ${ }^{1} 40 \%$ to $60 \%$ of patients with schizophrenia suffer from life-long impairment arising from this illness. These factors can reduce social function, and can lead to long-term hospitalization, increasing morbidity cost, and consumption of health care resources. The Global Burden of Disease Study reported that $0.4 \%$ of the total disability adjusted life years across all diseases could be attributed to schizophrenia in 1990 , and this figure had increased to $0.6 \%$ by $2010 .^{2}$

Schizophrenia has been recognized as the most expensive disorder among all psychiatric disorders in terms of health care expenditure per patient. ${ }^{3}$ The overall rates 


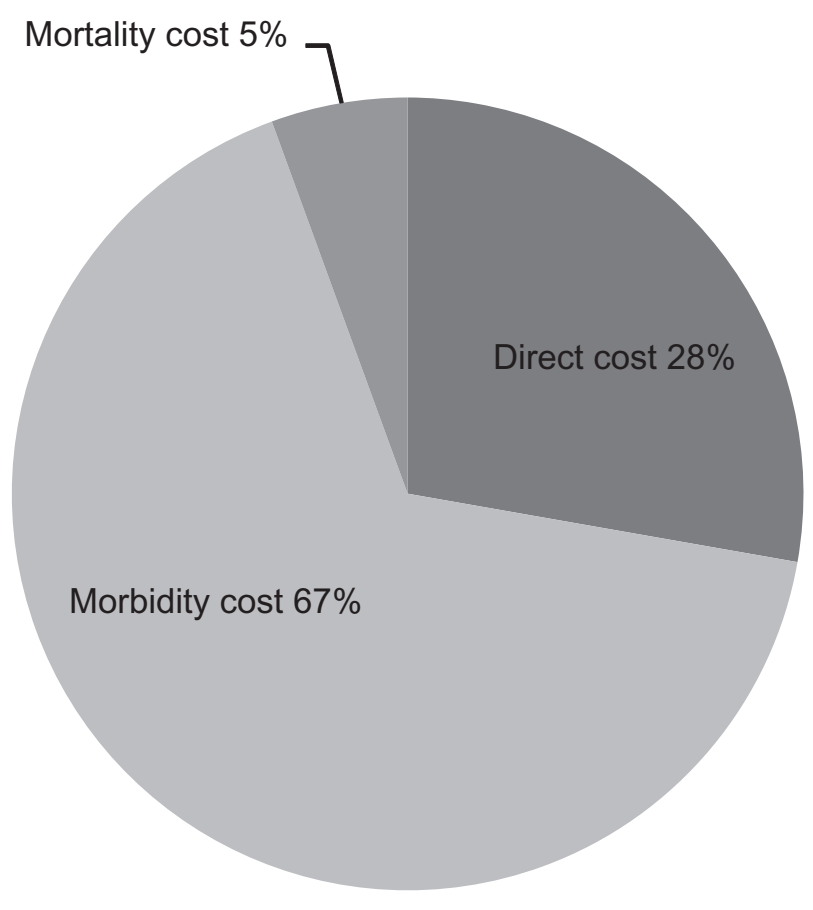

Figure I Proportion of each cost component.

of national health expenditure for schizophrenia in the late 1980s and 1990 s were $1.5 \%$ in the UK $;{ }^{4} 2 \%$ in the Netherlands ${ }^{5}{ }^{5}$ France, ${ }^{6}$ and Belgium; ${ }^{7}$ and $2.5 \%$ in the USA. ${ }^{8}$

Due to the rapidly aging population and the increased cost associated with advances in health technology, the importance of the efficient use and reasonable allocation of scarce health care resources has become more crucial than ever before in the context of Japanese health policy development. Estimating the societal burden of each illness and clarifying what effective and efficient interventions can be performed should be viewed as consecutive steps for achieving this process. With respect to schizophrenia, a much larger number of people with schizophrenia (ie, the patients of the post-World War II baby-boom generation) are also surviving into old age. In an inpatient-dominated mental health system, associated costs could rise even more. Therefore, the efficient use of scarce resources becomes more important. Several studies have already been conducted to estimate the social burden caused by schizophrenia in the UK, US, and other countries. ${ }^{9-13} \mathrm{~A}$ study examining the societal burden caused by depression in Japan ${ }^{14}$ has also been reported, but there are no published studies on the societal burden of schizophrenia in Japan, to the authors' knowledge.

\section{Objective}

The objective of this study was to evaluate the cost of schizophrenia in Japan in 2008 from a societal perspective.

\section{Methods}

A prevalence-based approach was adopted to measure the total cost of schizophrenia among adults (20 years of age or more) in Japan in 2008. 2008 data were used as 2008 is the most recent year for which all necessary data were available. Schizophrenia is defined as disorders coded as F20.0-F20.9 in International Classification of Diseases (ICD)-10. A broader definition of schizophrenia such as that used in the Global Burden of Disease Study ${ }^{2}$ would be F20.0-F29 in ICD-10. However, using such a broad definition would include other psychotic disorders such as schizoaffective disorder and acute and transient psychotic disorders. To avoid overinclusivity we judged it appropriate to adopt the earlier definition.

The costs included in the analysis were direct cost, morbidity cost, and mortality cost. The informal care costs, which are defined as the costs of care provided by nonprofessional caregivers such as family, friends, acquaintances, or neighbors of a patient, for which they do not have to be financially compensated ${ }^{15}$ were excluded because no reliable data are available to estimate this cost in Japan.

This study was conducted from a societal perspective. Data were collected from publicly available statistics and reports. We acknowledged the possibility that data derived from these statistics varied depending on the year surveyed because the data were estimated by random sampling. Therefore, where previous data were available, ${ }^{16,17}$ data were checked and confirmed to be stable. Analyses were conducted according to conservative principles (ie, the avoidance of overestimates). The results are shown both in Japanese Yen (JPY) and US dollars (USD). Purchasing power parity between JPY and USD in 2008 (USD $1=$ JPY 116.8) was used to calculate the USD equivalent of each cost component.

\section{Direct costs}

\section{The health care costs covered by health insurance}

To calculate the health care costs covered by health insurance, we mainly used two Ministry of Health, Labour and Welfare data sources: the Patient Survey ${ }^{16}$ and the Survey of Medical Care Activities in Public Health Insurance. ${ }^{17}$ In Japan, universal health care is provided under public health insurance schemes. The volume of services provided under these schemes is reported annually by the Survey of Medical Care Activities in Public Health Insurance, ${ }^{17}$ while the number of the patients, categorized by diagnosis, utilizing health care services within these schemes is estimated every 3 years by the Patient Survey. ${ }^{16}$ 


\section{Outpatient costs}

Outpatient cost data were gathered from Patient Survey ${ }^{16}$ and the Survey of Medical Care Activities in Public Health Insurance. ${ }^{17}$ The Patient Survey reports were used to estimate the number of patients in each diagnostic category for all physical and mental diseases, while the Survey of Medical Care Activities in Public Health Insurance was used to obtain the total treatment expenses for all treatments covered by public health insurance for each diagnostic category for a period of 1 month.

Regarding schizophrenia, the Survey of Medical Care Activities in Public Health Insurance ${ }^{17}$ only reported the total combined outpatient costs for all psychotic disorders (ie, F20.0-F29: F2 group), aggregating costs associated with schizophrenia and schizoaffective disorder, etc. The costs specifically associated with schizophrenia were not reported separately. In order to account for this, the proportion of patients with schizophrenia among all the patients in the F2 group was estimated from the Patient Survey ${ }^{16}$ to calculate the cost specifically attributable to schizophrenia, under the assumption that the average outpatient cost among patients with different psychotic disorders was the same. The following formula was used to calculate the annual outpatient costs:

$$
C_{\text {sch-out }}=C_{f 2 \text { out }} \times \frac{N_{\text {sch-out }}}{N_{f 2 \text { out }}} \times 12,
$$

where $C_{\text {sch-out }}$ is the outpatient cost of schizophrenia, $C_{f 2-\text { out }}$ is the outpatient cost of the F2 group, $N_{\text {sch-out }}$ is the estimated number of the outpatients with schizophrenia, and $N_{f 2-o u t}$ is the estimated number of the outpatients with F2 group diagnoses.

\section{Inpatient costs}

Data on the cost of inpatient treatment was also obtained from the Patient Survey ${ }^{16}$ and the Survey of Medical Care Activities in Public Health Insurance. ${ }^{17}$ Similar to the reported outpatient costs above, only the total cost of the F2 group per month was available; consequently, the rate of schizophrenia among the F2 group in the Patient Survey was determined and used to calculate the inpatient treatment cost for schizophrenia. No difference was assumed to exist among the average treatment costs for the different disorders in the F2 group.

The formula calculating annual outpatient cost is as below:

$$
C_{s c h-i n}=C_{f 2-i n} \times \frac{N_{s c h-i n}}{N_{f 2-i n}} \times 12,
$$

where $C_{s c h-i n}$ is the inpatient cost of schizophrenia, $C_{f 2-i n}$ is the inpatient cost of the F2 group, $N_{\text {sch-in }}$ is the estimated number of inpatients with schizophrenia, and $N_{f 2-i n}$ is the estimated number of inpatients with F2 group diagnoses.

\section{Medication costs}

Only antipsychotics were included in previous studies calculating the medication costs for the treatment of schizophrenia. However, antipsychotics are also provided for patients with other psychiatric disorders. On the other hand, other medications, such as mood stabilizers, antidepressants, and anxiolytic drugs, are prescribed for many patients with schizophrenia. To resolve this problem, we estimated the medication costs for schizophrenia as the cost of all prescribed drugs, both psychotropic and non-psychotropic, for patients diagnosed as having schizophrenia, such as antidepressants, mood stabilizers, anxiolytic drugs, and antihypertensives.

While the Survey of Medical Care Activities in Public Health Insurance ${ }^{17}$ provided the total medication costs of the F2 group both for inpatients and outpatients, it did not provide the specific total costs for schizophrenia. The total medication cost for schizophrenia was calculated by multiplying the net costs for the F2 group by the proportion of patients with schizophrenia among the patients in the F2 group.

The formulae for calculating inpatient and outpatient medication costs are as follows:

$$
C_{s c h-i n-m}=C_{f 2-i n-m} \times \frac{N_{s c h-i n}}{N_{f 2-i n}} \times 12
$$

and

$$
C_{\text {sch-out-m }}=C_{f 2-\text { out }-m} \times \frac{N_{\text {sch-out }}}{N_{f 2-\text { out }}} \times 12 \text {, }
$$

where $C_{\text {sch-in-m }}$ and $C_{\text {sch-out-m }}$ are the inpatient and outpatient medication costs of schizophrenia, $C_{f 2-i n-m}$ and $C_{f 2-o u t-m}$ are the inpatient and outpatient medication costs of the F2 group, $N_{\text {sch-in }}$ and $N_{\text {sch-out }}$ are the estimated numbers of inpatients and outpatients with schizophrenia, and $N_{f 2-\text { in }}$ and $N_{f 2-\text { out }}$ are the estimated numbers of inpatients and outpatients with F2 group diagnoses. Medication costs covered by Japan's Diagnosis Procedure Combination/per-diem payment system were excluded from the inpatient medication costs calculated above, as these costs are already included in the inpatient cost of schizophrenia calculated in the previous section.

\section{Involuntary admission costs}

In Japan, there are two distinct types of formal admission: "medical protection admission" and "involuntary admission." 
Therefore, a patient can be admitted to hospital in three ways in Japan: (1) voluntary admission to which the patient consents; (2) medical protection admission, when a psychiatrist designated by law, specifically, the Law Related to Mental Health and Welfare of the Person with Mental Disorder, ${ }^{18}$ judges that a patient has mental disorder, requires inpatient treatment, and is not consenting, but a guardian of the patient agrees to the admission and treatment; or (3) involuntary admission, when two independent, designated psychiatrists' assessments conclude that a patient has a mental illness and presents a risk to themself or others.

The Law Related to Mental Health and Welfare of the Person with Mental Disorder, is described by the Law Society thusly:

To provide person(s) with mental disorder with medical care and protection, and in combination with the purpose of this Law is to Support Independence of Disabled Persons to offer necessary assistance for promoting their social rehabilitation, self-support, and participation in socio-economic activities, and to endeavor to prevent onset thereof, maintain, and promote mental health of the people in general, to thereby advance general well-being of the person(s) with mental disorder and to enhance mental health of the people in general. ${ }^{19}$

Under the arrangement for voluntary admissions and medical protection admissions, costs are met by health insurers in the usual way and so costs are captured in inpatient admission costs as described above. However, involuntary admission costs are met by a separate budget directly funded by the tax-payer and so need to be added to the stated inpatient costs above.

Involuntary admission costs were estimated by multiplying the point estimate of the total number of patients with schizophrenia admitted involuntarily by the average daily inpatient cost and by 365 days. The point estimate of the total number of patients with schizophrenia admitted involuntarily was derived from a Mental Health and Welfare document ${ }^{20}$ published in 2007 . The average daily inpatient cost was assumed to be the same as that of the inpatient cost under the health insurance schemes. The average daily inpatient cost under the health insurance schemes was estimated from the Survey of Medical Care Activities in Public Health Insurance. ${ }^{17}$ The proportion of patients with schizophrenia admitted involuntarily among all the involuntarily admitted patients was calculated as follows. First, the total number of involuntarily admitted patients was multiplied by the rate of F2 group patients among all the involuntarily admitted patients. Then, the result was multiplied by the ratio of patients with schizophrenia among the F2 group patients derived from the Patient Survey ${ }^{16}$ and the Survey of Medical Care Activities in Public Health Insurance. ${ }^{17}$

\section{Costs of provision under the Medical Care and Supervision Act in Japan}

The Medical Care and Supervision Act in Japan defines the provision of appropriate medical care and treatment in order to promote social rehabilitation for persons who have committed serious crimes under the condition of insanity or diminished capability. ${ }^{21}$ The budget for the execution of mental health supervision and the execution of medical care provision under the Medical Care and Supervision Act in Japan was used as the starting point for calculating the cost of provision under the Medical Care and Supervision Act in Japan. The rate of patients with schizophrenia among all the patients treated under the Medical Care and Supervision Act in Japan was not available but was calculated by hypothesizing that the rate of the number of F2 group patients among all psychiatric patients and the rate of the number of patients with schizophrenia among all the F2 group patients under the Medical Care and Supervision Act in Japan would be the same as the rate of the number of $\mathrm{F} 2$ group patients among all the psychiatric patients admitted involuntarily ${ }^{20}$ and the rate of the number of patients with schizophrenia among all the F2 group patients under the health insurance schemes from the Patient Survey ${ }^{16}$, respectively.

\section{Social service costs}

The cost of all services provided under the Services and Supports for Persons with Disabilities Act was regarded as the total social service costs. As described by the Ministry of Health, Labour and Welfare, this Act aims to improve the welfare of persons (adults) and children with disabilities through the provision of benefits for necessary disability welfare services and provision of other forms of support to enable persons (adults) and children with disabilities to live independent daily or social lives according to their respective abilities and aptitudes. ${ }^{22}$ The costs of other social services provided outside the scope of this act, such as the medical assistance costs covered by public assistance (ie, financial support for medical treatment costs by local government for those under public assistance), and the costs for health centers and group homes, should have been included in this cost; however, these components had to be excluded from the analysis because of the lack of available data. 
The data regarding service use related to the Services and Supports for Persons with Disabilities Act was derived from a Mental Health and Welfare document ${ }^{20}$ and a study titled "Survey of patients with mental disorders attending mental health clinics who are not involved in social activities currently, and research to improve the support of patients wishing to become involved in social activities (Asukuri research)" conducted by the Japanese Association of Mental Health Services in 2007. ${ }^{23}$ The Mental Health and Welfare document ${ }^{20}$ reported the total number of patients using outpatient services provided by the Services and Supports for Persons with Disabilities Act, such as a support office for continuous employment (type A), a support office for continuous employment (type B), a transition support office for employment, and a rehabilitation service office, all irrespective of psychiatric diagnosis. Consequently, the specific number of patients with schizophrenia utilizing these services was unclear.

The Asukuri research ${ }^{23}$ provided data on the community services described above under the Services and Supports for Persons with Disabilities Act for psychiatric patients attending 113 clinics in December 2007, stratified according to diagnosis. The research clarified the ratio of patients with schizophrenia among all the patients using these services. This allowed the total number of patients with schizophrenia per year who utilized services provided by the Services and Supports for Persons with Disabilities Act from the Mental Health and Welfare document ${ }^{20}$ to be estimated by multiplying the total number of patients who accessed services provided by the Services and Supports for Persons with Disabilities Act by the ratio of patients with schizophrenia among all the patients included in the Asukuri research. The cost of the Services and Supports for Persons with Disabilities Act was calculated by multiplying this total number of patients with schizophrenia by the average daily cost (JPY 4261: USD 36.5) for services under the Services and Supports for Persons with Disabilities Act.

\section{Indirect costs}

Indirect costs are comprised of morbidity and mortality costs. Morbidity costs occur when patients are not able to function normally as a result of their illness, ${ }^{24}$ while mortality costs arise when patients die as a result of suicide at an age earlier than the average life expectancy.

\section{Morbidity costs}

Morbidity costs reflect the productivity loss caused by absence from work (ie, absenteeism) and productivity loss while at work (ie, presenteeism) and that due to unemployment (ie, unemployment costs). Larg and $\mathrm{Moss}^{25}$ proposed components such as absenteeism, presenteeism, unemployment, premature death, treatment-related time off work, unwanted job changes, loss of opportunities for promotion and education, and loss of unpaid production while ill as potential production losses (ie, morbidity and mortality costs). However, no reliable data in Japan are available with regard to absenteeism, presenteeism, treatment-related time off work, unwanted job changes, loss of opportunities for promotion and education, and loss of unpaid production while ill, so these costs were omitted from the analysis and only the unemployment costs were reflected in the morbidity costs. Although the components we were able to include in the morbidity costs were limited, we note this problem has confronted other authors, and previous studies ${ }^{10,26}$ have included only unemployment or unemployment and absenteeism as morbidity costs as well. In the analysis we assumed that the gap between the employment rate of the general population and that of patients with schizophrenia was a result of the illness, and the costs caused by this gap were included in the analysis as unemployment costs.

The sex/age-specific unemployment cost was calculated by multiplying the sex/age-specific number of patients with schizophrenia by the sex/age-specific employment rate differences between the general population and patients with schizophrenia, and the average yearly earning using the following formula:

$$
U C=\operatorname{Po} \times \operatorname{Pr} \times\left(E_{g e n}-E_{\text {schi }}\right) \times W,
$$

where $U C$ is the unemployment cost, $P o$ is the population size, $\operatorname{Pr}$ is the point prevalence of schizophrenia, $E_{g e n}$ is the employment rate of the general population, $E_{\text {schi }}$ is the employment rate of patients with schizophrenia, and $W$ is the average yearly earning. The total unemployment cost was estimated by summating each category of sex/age-specific unemployment costs.

The employment rate of the general population and that of patients with schizophrenia were derived from the Labour Force Survey ${ }^{27}$ and the Asukuri research, ${ }^{23}$ respectively.

The prevalence rate should be derived from general population samples, rather than samples of patients accessing health care, because some individuals with schizophrenia do not access health care. We conducted a literature review to obtain a precise sex/age-specific prevalence rate for Japan. Saha et $\mathrm{al}^{28}$ conducted a systematic review regarding the prevalence of schizophrenia in the general population that included studies performed in Japan. ${ }^{29-34}$ However, the subjects of these articles 
were elderly people, college students, or patients receiving treatment, rather than the general population. Consequently, we felt that these results were probably not representative of Japan overall. Because of the lack of such data, we assumed that only those subjects who accessed treatment could be regarded as suffering from schizophrenia in Japan and calculated the 12-month prevalence by dividing the sex/age-specific number of patients with schizophrenia accessing treatment by that of the general population. ${ }^{35}$ The total number of patients under treatment was obtained from the Patient Survey. ${ }^{16}$ Although the Patient Survey is based on a 1-day survey, the total number of patients under treatment represents all patients receiving treatment irrespective of having a treatment on the date surveyed or not by calculating using the formula below:

$$
N t=N i+N_{f v}+N_{r v} \times D \times(6 / 7)
$$

where $N t$ is the total number of patients under treatment, $N i$ is the number of inpatients, $N_{f v}$ is the number of firstvisit outpatients, $N_{r v}$ is the number of outpatients under follow up, and $D$ is the average duration between follow up appointments.

The prevalence rate obtained through this procedure was the point prevalence, rather than the 12-month prevalence. In general, however, the morbidity period of schizophrenia is relatively long. Consequently, we assumed that the discrepancy between the point prevalence and that of the 12-month prevalence was minimal and regarded the point prevalence as being equivalent to the 12-month prevalence. The details are shown in Table 1.

The sex/age-specific employment rates of patients with schizophrenia were provided by the Asukuri research. ${ }^{23}$ In the data provided, schizophrenia was not differentiated from other illness coded as belonging to the F2 group. Consequently, the employment rate of the F2 group is regarded as being the same as that of the patients with schizophrenia. Finally, the sex/age-specific average yearly earnings were calculated from the Basic Survey on Wage Structure. ${ }^{36}$ All the parameters and their distributions used for calculating morbidity costs are shown in Table 2 .

\section{Mortality costs}

The definition of mortality cost was the net present value (NPV) of the expected lifetime earnings loss caused by suicides because of schizophrenia. It was calculated by multiplying the estimated number of suicides arising from schizophrenia by the NPV of the expected lifetime earnings. The NPV was calculated using the formula below:
Table I Prevalence and the number of the patients with schizophrenia

\begin{tabular}{llll}
\hline Age & $\begin{array}{l}\text { Population } \\
\text { (thousand) }^{\mathrm{a}}\end{array}$ & Prevalence $^{\mathrm{b}}$ & $\begin{array}{l}\text { Number of patients } \\
\text { (thousand) }\end{array}$ \\
\hline Male & & & \\
$20-24$ & 3650 & 0.004 & 13 \\
$25-29$ & 3892 & 0.005 & 18 \\
$30-34$ & 4565 & 0.007 & 33 \\
$35-39$ & 4858 & 0.009 & 42 \\
$40-44$ & 4236 & 0.009 & 40 \\
$45-49$ & 3906 & 0.011 & 43 \\
$50-54$ & 3904 & 0.011 & 41 \\
$55-59$ & 4865 & 0.010 & 51 \\
$60-64$ & 4374 & 0.009 & 39 \\
$65-69$ & 3845 & 0.007 & 26 \\
$70-$ & 8199 & 0.004 & 34 \\
Total & 50,294 & & 380 \\
Female & & & 15 \\
$20-24$ & 3455 & 0.004 & 22 \\
$25-29$ & 3738 & 0.006 & 29 \\
$30-34$ & 4430 & 0.007 & 32 \\
$35-39$ & 4750 & 0.007 & 37 \\
$40-44$ & 4170 & 0.009 & 35 \\
$45-49$ & 3875 & 0.009 & 39 \\
$50-54$ & 3918 & 0.010 & 48 \\
$55-59$ & 4972 & 0.010 & 43 \\
$60-64$ & 4584 & 0.009 & 69 \\
$65-69$ & 4195 & 0.008 & \\
$70-$ & 11,977 & 0.006 & \\
Total & 54,064 & & \\
\hline & & & \\
\hline
\end{tabular}

Notes: a Derived from Vital Statistics; ${ }^{35}{ }^{\text {c}}$ calculated based on data from Vital Statistics ${ }^{35}$ and the Patient Survey. ${ }^{16}$

$$
N P V_{q}=\sum_{n=q}^{1} \frac{E_{n} W_{n}}{(1+i)^{n \cdot q}}
$$

where $q$ is the age at the time of death by suicide, $n$ is the age of the patients if they had survived, $l$ is the life expectancy, $E_{n}$ is the employment rate at the age of $n, W_{n}$ is the average yearly earning at the age of $n$, and $i$ is the discount rate.

The total number of suicides was obtained from the Statistics of Suicide. ${ }^{37}$ The ratio of suicide caused by schizophrenia was obtained from a report by Kaga. ${ }^{38}$ The reason that this ratio was chosen was that although the sample size was relatively small $(\mathrm{n}=76)$, a psychological autopsy had been conducted for 76 of the suicides, and the demographic data of the sample was representative of the data for all suicide cases in Japan.

The Basic Survey on Wage Structure ${ }^{36}$ and the Labour Force Survey ${ }^{27}$ were referenced to estimate the lifetime earnings. The discounting rate was set at $3 \%$, as this rate has been used in recent international studies. ${ }^{39}$ All the parameters and their distributions included in the model to calculate the mortality cost are shown in Table 3. 


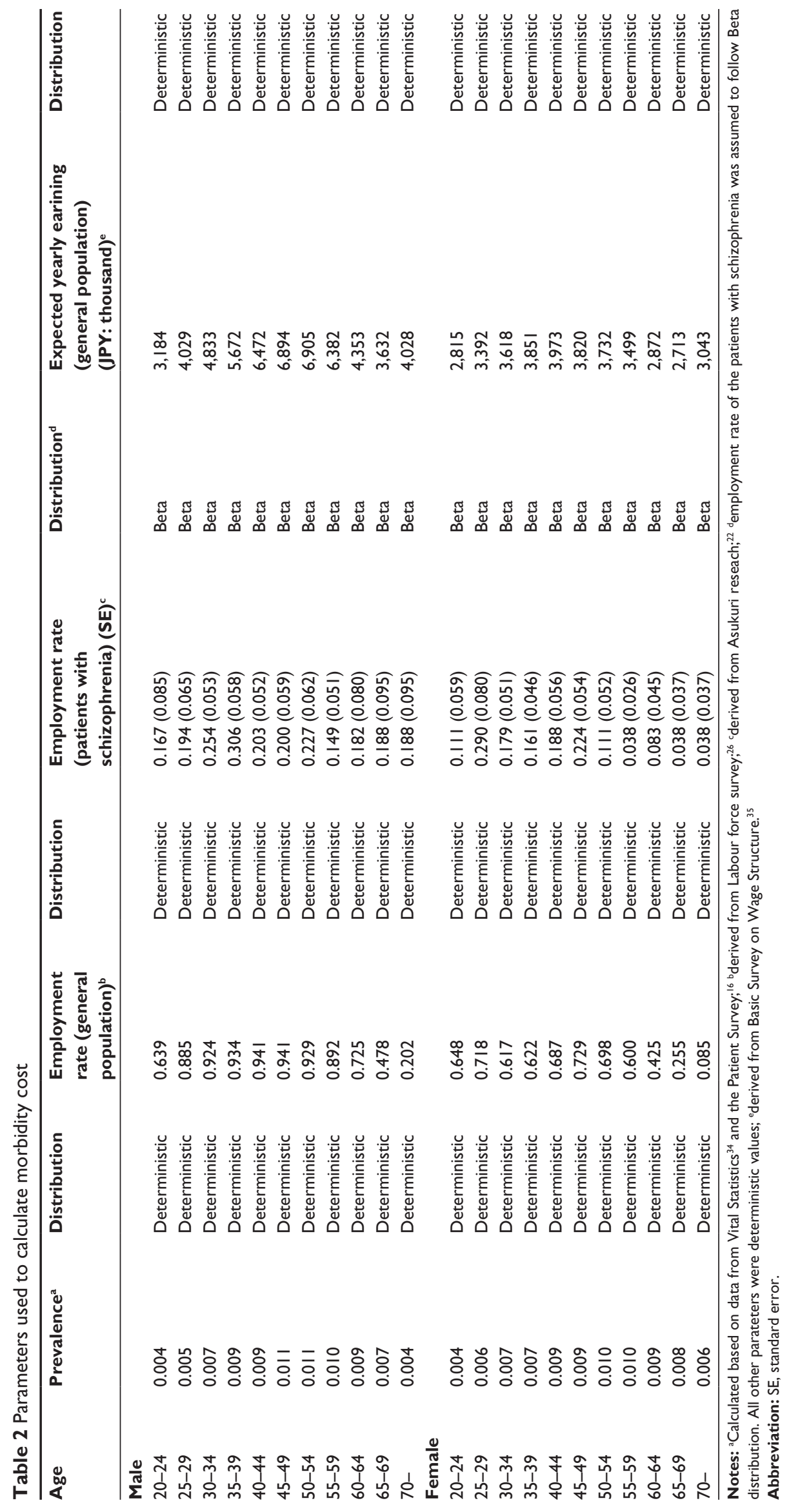




\section{Uncertainty}

We collected the best evidence available when performing the analyses. However, some uncertainty regarding the parameters remains. The nature of the available data was responsible for this limitation. Accordingly, in order to ensure the robustness of the estimated cost of schizophrenia, probabilistic sensitivity analyses (PSA) ${ }^{40,41}$ were conducted to calculate the mean morbidity and mortality costs and their standard errors (SEs). The probability distributions around the input variables were based on the SEs quoted in or calculated from previous reports. We used the PSA function in Excel 2007 (Microsoft Corporation, Redmond, WA, USA) for this, which is basically a macro allowing multiple recalculations of Excel spreadsheet data using a different value from the uncertainty distribution defined for the input variables. We calculated the mean values and their SEs for the output variables from amongst 5000 values that were generated in this manner. The results were then presented to three significant digits together with their SEs.

\section{Results \\ Direct costs}

The direct costs of schizophrenia in Japan in 2008 were estimated to be JPY 770 billion (USD 6.59 billion). The health care costs covered by health insurance were JPY 751 billion (USD 6.43 billion). The involuntary admission costs were JPY 6.18 billion (USD 53 million), the cost of the Medical Care and Supervision Act in Japan was JPY 9.54 billion (USD 82 million), and the social service costs were JPY 3.48 billion (USD 30 million). The outpatient and inpatient costs were JPY 148 billion (USD 1.27 billion) and
JPY 603 billion (USD 5.16 billion), respectively (including medication costs). The details are shown in Tables 4 and 5 .

\section{Indirect cost}

\section{Morbidity cost (unemployment cost)}

The point prevalences, stratified according to sex and age, ranged from $0.4 \%-1.1 \%$, as indicated in Table 1 . The employment rates for individuals aged 25 to 59 years were $89 \%$ to $94 \%$ for men and $60 \%$ to $73 \%$ for women in the general population, while those for patients with schizophrenia were $15 \%$ to $31 \%$ for men and $4 \%$ to $29 \%$ for women (Table 2). By multiplying the differences in the employment rates between the general population and the patients with schizophrenia by the expected yearly earning, the lost employment costs were calculated. Because the employment rate of the patients with schizophrenia used in the calculation contained some uncertainty, the mean and the SE of the unemployment costs were calculated by conducting a PSA to reflect this uncertainty in the results. As a result, the mean unemployment cost was JPY 1.85 trillion (USD 15.8 billion) and its SE was JPY 706 million (USD 6 million) (Table 6).

\section{Mortality cost}

The total number of suicides in Japan in 2008 was 31,638. The number of suicides stratified according to sex and age is shown in Table 3. The ratio of suicides attributed to schizophrenia among all the suicides was cited from Kaga (ie, 0.095$).{ }^{38}$ The mortality costs were estimated by multiplying the sex/age-specific number of suicides among patients with schizophrenia by the sex/age-specific expected lifetime

Table 3 Parameters for calculation of the mortality cost

\begin{tabular}{|c|c|c|c|c|c|c|}
\hline Age & $\begin{array}{l}\text { Number } \\
\text { of suicides }^{\mathrm{a}}\end{array}$ & Distribution & $\begin{array}{l}\text { Expected lifetime } \\
\text { earning (JPY: thousand) }\end{array}$ & Distribution & $\begin{array}{l}\text { Rate of suicides caused } \\
\text { by schizophrenia (SE)c }\end{array}$ & Distribution \\
\hline \multicolumn{7}{|l|}{ Male } \\
\hline $20-29$ & 2373 & Deterministic & $12 \mid, 766$ & Deterministic & $0.095(0.034)$ & Beta \\
\hline $30-39$ & 3396 & Deterministic & 119,104 & Deterministic & $0.095(0.034)$ & Beta \\
\hline $40-49$ & 3852 & Deterministic & 94,737 & Deterministic & $0.095(0.034)$ & Beta \\
\hline $50-59$ & 4986 & Deterministic & 52,633 & Deterministic & $0.095(0.034)$ & Beta \\
\hline $60+$ & 7639 & Deterministic & I I,489 & Deterministic & $0.095(0.034)$ & Beta \\
\hline Unkown & 204 & Deterministic & 63,317 & Deterministic & $0.095(0.034)$ & Beta \\
\hline \multicolumn{7}{|l|}{ Female } \\
\hline $20-29$ & 1065 & Deterministic & 57,818 & Deterministic & $0.095(0.034)$ & Beta \\
\hline $30-39$ & 1454 & Deterministic & 50,972 & Deterministic & $0.095(0.034)$ & Beta \\
\hline $40-49$ & 1118 & Deterministic & 38,805 & Deterministic & $0.095(0.034)$ & Beta \\
\hline $50-59$ & 1377 & Deterministic & 20,822 & Deterministic & $0.095(0.034)$ & Beta \\
\hline $60+$ & 4154 & Deterministic & 4704 & Deterministic & $0.095(0.034)$ & Beta \\
\hline Unkown & 20 & Deterministic & 24,791 & Deterministic & $0.095(0.034)$ & Beta \\
\hline
\end{tabular}

Notes: ${ }^{a}$ Derived from Statistics of Suicides in 2008, ${ }^{37}$ bderived from Basic Survey on Wage Structure; ${ }^{36}$ cderived from Kaga. ${ }^{38}$ Abbreviation: SE, standard error. 
Table 4 Inpatient and outpatient costs

\begin{tabular}{ll}
\hline & Total costs (JPY: million) \\
\hline Health care costs under health insurance & \\
Inpatient costs & 602,771 \\
Outpatient costs & 148,047 \\
Involuntary admission costs* & 6184 \\
\hline
\end{tabular}

Note: *Involuntary admission is classified into inpatient cost.

earnings. Because the ratio of suicides attributed to schizophrenia among all the suicides was somewhat uncertain, a PSA was performed to clarify the mean cost and its SE. The mean mortality cost and its SE were JPY 155 billion (USD 1.33 billion) and JPY 783 million (USD 7 million), respectively (Table 6).

\section{Discussion}

To our knowledge, this is the first study to evaluate the societal cost of schizophrenia in Japan. The results showed that the total cost of schizophrenia was JPY 2.77 trillion (USD 23.7 billion) and the indirect costs constituted the greatest part of the total cost ( $72 \%$ of the total cost) (Table 7) (Figure 1). Of note, previous studies also reported that the indirect costs accounted for a major part of the total costs ( $71 \%$ in the US in $1991 ; ;^{12} 52 \%$ in the US in $2002 ;{ }^{11} 52 \%$ in the UK in $\left.2004 / 2005^{10}\right)$. However, international comparisons of the costs of schizophrenia are quite difficult to make, not only because health and social care systems differ significantly internationally, but also because the methodology of each study varies considerably. Therefore, considerable caution should be exercised when comparing the results in this study with those in other countries. Particularly, there is too much uncertainty around estimates of indirect costs to allow meaningful comparison. However, less uncertainly exists in estimates of direct costs, and so here we focus on comparing only a subset of specific elements of the direct costs of schizophrenia between countries in which health care expenditure against gross domestic product is similar in order to draw some preliminary conclusions. We would like

Table 5 Direct costs

\begin{tabular}{ll}
\hline & Point estimate \\
\cline { 2 - 2 } & (JPY: million) \\
\hline Health care cost & 766,545 \\
Health care care cost under health insurance schema & 750,818 \\
Involuntary admission cost & 6184 \\
The medical care and supervision act cost & 9543 \\
Social service cost & 3477 \\
Total direct cost & 770,022 \\
\hline
\end{tabular}

Table 6 Morbidity and mortality cost

\begin{tabular}{lll}
\hline & Mean & (JPY: million) \\
\cline { 3 - 3 } & & SE \\
\hline Morbidity cost & $1,849,65 \mathrm{I}$ & 706 \\
Unemployment cost & $1,849,65 \mathrm{I}$ & 706 \\
Mortality cost & 154,708 & 783 \\
Total indirect cost & $2,004,359$ & 1067 \\
\hline
\end{tabular}

Abbreviation: SE, standard error.

to make some cautious comparisons using a study reporting English data by Mangalore and Knapp. ${ }^{10}$

Because the number of psychiatric beds per capita in Japan is approximately four times greater than that in the $\mathrm{UK},{ }^{42}$ many of those who reside in other facilities outside hospitals such as care homes and group homes in England are likely to reside in a hospital in Japan. To account for this difference, it is more appropriate to compare health care costs in the study reported above with health and social care, and institutional costs in aggregate reported by Mangalore and Knapp for England. ${ }^{10}$

Mangalore and Knapp indicate that health and social care, and institutional costs in England are approximately GBP 1.79 billion. ${ }^{10}$ Considering the population size (128 million in Japan, ${ }^{35} 53$ million in England ${ }^{43}$ ) and currency exchange rate (GBP $1=$ JPY 183: purchasing power parity), ${ }^{42}$ this figure would be equivalent to JPY 0.789 trillion of direct costs of schizophrenia for Japan, implying that differences in direct costs between the two countries are surprisingly small. Furthermore, inpatient costs constituted $80 \%$ of the total health care costs (including the involuntary admission costs) in Japan in this study (Table 4), while in England the comparable figure would be $77 \%$, suggesting limited differences in costs of institutional care for schizophrenia. Given the major differences between the UK and Japan in how care for schizophrenia is organized and delivered (inpatient versus community), the drugs available to treat schizophrenia, and the rates of comorbidity with illicit drug use, these differences are surprisingly small.

Comparing the cost of schizophrenia to other mental disorders in Japan, a report published in $2011^{45}$ estimated the costs of depression and anxiety disorders in 2008 using the same methodology. This 2011 report and the result of our study reported here, when taken together indicate that for all three of these mental disorders the indirect costs accounted for the greater part of the societal cost $(72 \%$ in schizophrenia; $91 \%$ in depression; and $98 \%$ in anxiety disorders). Further, the proportion of each component in the making up of the indirect costs among these three disorders would appear 
Table 7 Total cost of schizophrenia

\begin{tabular}{|c|c|c|c|c|}
\hline & \multicolumn{2}{|c|}{ Point estimate or mean } & \multicolumn{2}{|l|}{ SE } \\
\hline & (JPY: million) & (USD: million) & (JPY: million) & (USD: million) \\
\hline Direct cost & 770,022 & 6593 & - & - \\
\hline Health care cost & 766,545 & 6563 & - & - \\
\hline Health care care cost under health insurance schema & 750,818 & 6428 & - & - \\
\hline Involuntary admission cost & 6184 & 53 & - & - \\
\hline The medical care and supervision act cost & 9543 & 82 & - & - \\
\hline Social service cost & 3477 & 30 & - & - \\
\hline Indirect cost & $2,004,359$ & $|7,16|$ & 1,067 & 9 \\
\hline Morbidity cost & $|, 849,65|$ & 15,836 & 706 & 6 \\
\hline Unemployment cost & $|, 849,65|$ & 15,836 & 706 & 6 \\
\hline Mortality cost & 154,708 & 1325 & 783 & 7 \\
\hline Total cost & $2,774,381$ & 23,753 & 1,067 & 9 \\
\hline Total cost per patient (JPY/USD) & $3,538,751$ & 30,298 & $|, 36|$ & 12 \\
\hline
\end{tabular}

Abbreviation: SE, standard error.

to reflect the characteristics of each disorder. In schizophrenia, the costs imposed by unemployment constituted the largest component, accounting for about $92 \%$, while in depression and anxiety disorders, absenteeism and presenteeims is the biggest part of the indirect cost (53\% in depression and 59\% in anxiety disorders). Absenteeism and presenteeism were not included as cost components in our estimation of the cost of schizophrenia. However, considering the low employment rate and the low prevalence rate of patients with schizophrenia compared to those with depression or anxiety disorders (both approximately one third of the employment rate and prevalence rate of depression based on Sado et al), ${ }^{45}$ even if the cost of these components were estimated, it would not have had a great influence on the composition of the indirect costs. (An approximate estimate of the absenteeism and presenteeism costs in schizophrenia might be JPY 170 billion [USD 1.46 billion]; less than 10\% of the unemployment cost of schizophrenia).

These findings indicates that, in schizophrenia, the greater part of the indirect costs occurred outside of the workplace (ie, unemployment costs), while in depression and anxiety disorders, the cost inside the workplace (ie, absenteeism and presenteeism) constituted the largest component. Based on these findings, to reduce the societal burden caused by schizophrenia, future research should focus more on how to improve employment rather than an intervention for absenteeism and presenteeism. In order to achieve this, more attention should be paid to improvement not only of the symptoms of schizophrenia but also to the social function of patients.

\section{Limitations}

Although we were able to include a variety of the societal costs of schizophrenia in this study, there remain some costs that we were unable to include. For example, some costs such as the medical assistant costs covered by public assistance, a large part of social service costs, informal care costs, and the costs of absenteeism/presenteeism were not analyzed in this study because of the lack of available data. In particular, with regard to social service costs, although ideally a variety of services such as health centers and group homes should have been included, only the costs directly associated with the Services and Supports for Persons with Disability Act were analyzed because it was not possible to obtain data about the extent to which these other costs were attributable specifically to schizophrenia. Consequently, the burden of schizophrenia will have been underestimated. Furthermore, the fact that the data utilized in the analyses were derived from a variety of sources is another limitation. Data for 2008, or the closest year available, were used. When data with a broad sampling was impossible to obtain, smaller samplings were used. Although such limitations are inevitable in this type of study, they may have increased the uncertainty of the present results. These limitations should be taken into consideration when interpreting the present results. To assess the burden more fully, data related to informal care and productivity loss at work will be crucial in future studies. Furthermore, precise data regarding the employment rates and the suicide rate of patients with schizophrenia could improve the accuracy of the results.

\section{Acknowledgment}

This study was in part supported by a grant from the Ministry of Health, Labour and Welfare of Japan (H22-SHOGAI-36). We are grateful for the support and many technical comments we received from the staff members of the research team, Professor Shunya Ikeda, Dr Kunitoshi Hatou, Dr Daisuke 
Fujisawa, Dr Atsuo Nakagawa, and Ms Sayuri Takechi. We would also like to thank Dr Hiroyuki Hirakawa and the other staff members of the Asukuri research group for permitting us to use the results of the Asukuri research for part of this research. The Asukuri research was supported by a grant from Ministry of Health, Labour and Welfare of Japan (H19SHOGAI-79).

\section{Disclosure}

The authors report no conflicts of interest in this work.

\section{References}

1. Crown WH, Neslusan C, Russo PA, Holzer S, Ozminkowski R, Croghan T. Hospitalization and total medical costs for privately insured persons with schizophrenia. Adm Policy Ment Health. 2001;28(5): 335-351.

2. Murray CJ, Vos T, Lozano R, et al. Disability-adjusted life years (DALYs) for 291 diseases and injuries in 21 regions, 1990-2010: a systematic analysis for the Global Burden of Disease Study 2010. Lancet. 2013;380(9859):2197-2223.

3. Rössler W, Salize HJ, van Os J, Riecher-Rössler A. Size of burden of schizophrenia and psychotic disorders. Eur Neuropsychopharmacol. 2005;15(4):399-409.

4. Knapp M. Costs of schizophrenia. Br J Psychiatry. 1997;171:509-518.

5. Evers SM, Ament AJ. Costs of schizophrenia in The Netherlands. Schizophr Bull. 1995;21(1):141-153.

6. Rouillon F, Dansette GY, Le Floch C. Therapeutic management of schizophrenic patients and its cost. Encephale. 1994;20(3):303-309. French.

7. De Hert M, Thys E, Boydens J, et al. Health care expenditure on schizophrenia patients in Belgium. Schizophr Bull. 1998;24(4):519-527.

8. Rupp A, Keith SJ. The costs of schizophrenia. Assessing the burden. Psychiatr Clin North Am. 1993;16(2):413-423.

9. Guest JF, Cookson RF. Cost of schizophrenia to UK Society. An incidence-based cost-of-illness model for the first 5 years following diagnosis. Pharmacoeconomics. 1999;15(6):597-610.

10. Mangalore R, Knapp M. Cost of schizophrenia in England. J Ment Health Policy Econ. 2007;10(1):23-41.

11. Wu EQ, Birnbaum HG, Shi L, et al. The economic burden of schizophrenia in the United States in 2002. J Clin Psychiatry. 2005;66(9): 1122-1129.

12. Wyatt RJ, Henter I, Leary MC, Taylor E. An economic evaluation of schizophrenia - 1991. Soc Psychiatry Psychiatr Epidemiol. 1995;30(5): 196-205.

13. Rice DP, Miller LS. The economic burden of schizophrenia: conceptual and methodological issues, and cost estimates. In: Moscarelli M, Rupp A, Sartorius N, editors. Handbook of Mental Health Economics and Health Policy, vol 1: Schizophrenia. New York: John Wiley \& Sons; 1996:321-334.

14. Sado M, Yamauchi K, Kawakami N, et al. Cost of depression among adults in Japan in 2005. Psychiatry Clin Neurosci. 2011;65(5):442-450.

15. Brouwer WRF, Koopmanschap M. Costing in economic evaluations. In: Drummond M, McGuire A, editors. Economic Evaluation in Health Care: Merging Theory with Practice. New York: Oxford University Press; 2001:82.

16. Ministry of Health, Labour and Welfare of Japan. Patient Survey in 2008 (Kanja Chosa). Tokyo: Ministry of Health Labour and Welfare of Japan; 2009. Japanese.

17. Ministry of Health, Labour and Welfare of Japan. Survey of Medical Care Activities in Public Health Insurance in 2008 (Shakai Iryo Shinryo Koibetsu Chosa). Tokyo: Ministry of Health Labour and Welfare of Japan; 2009. Japanese.
18. Ministry of Health, Labour and Welfare of Japan. [Webpage on the Internet]. [Law Related to Mental Health and Welfare of the Person with Mental Disorder]. Tokyo:Ministry of Health Labour and Welfare of Japan; 2011 [cited February 22, 2013]. Available from: http://www.mhlw.go.jp/kokoro/nation/law.html. Accessed February 22, 2013.

19. Shiraishi H, Ohi S. Law Related to Mental Health and Welfare of the Person with Mental Disorder [translation]. Asake-City: Toyo University; 2010. Available from: http://www.npo-jam.org/en/pdf/ en_law_001_2010.pdf. Accessed January 28, 2013.

20. Ministry of Health, Labour and Welfare of Japan. Mental Health and Welfere Document in 2008 (Seishin Hoken Fukushi Shiryo). Tokyo: Ministry of Health Labour and Welfare of Japan; 2009. Japanese.

21. Ministry of Health, Labour and Welfare of Japan [webpage on the Internet]. [The Medical Care and Supervision Act in Japan]. Tokyo: Ministry of Health Labour and Welfare of Japan; 2003 [cited January 6, 2013]. Available from: http://www.mhlw.go.jp/bunya/shougaihoken/ sinsin/gaiyo.html. Accessed January 28, 2013.

22. Ministry of Health, Labour and Welfare of Japan. Services and Supports for Persons with Disabilities Act. Tokyo: Ministry of Health Labour and Welfare of Japan; 2006 [cited January 13, 2013]. Available from: http:// www.mhlw.go.jp/topics/2005/02/dl/tp0214-1b.pdf. Accessed January 28, 2013. Japanese.

23. Japanese Association of Mental Health Services. Survey of Patients with Mental Disorders Attending Mental Health Clinics Who Are Not Involved in Social Activities Currently and Research to Improve the Support of Patients Wishing to Become Involved in Social Activities (Asukuri research). Tokyo: Ministry of Health, Labour and Welfare of Japan; 2008. Japanese.

24. Kind P, Sorensen J. The costs of depression. Int Clin Psychopharmacol. 1993;7(3-4):191-195.

25. Larg A, Moss JR. Cost-of-illness studies: a guide to critical evaluation. Pharmacoeconomics. 2011;29(8):653-671.

26. McCrone P, Dhanasiri S, Patel A, Knapp M, Lawton-Smith S. Paying the Price: The Cost of Mental Health Care in England to 2026. London: King's Fund; 2008.

27. Ministry of Internal Affairs and Communications of Japan. Labour Force Survey in 2008 (Rodoryoku Chosa). Tokyo: Ministry of Internal Affairs and Communications of Japan; 2009. Japanese.

28. Saha S, Chant D, Welham J, McGrath J. A systematic review of the prevalence of schizophrenia. PLoS Med. 2005;2(5):e141.

29. Jablensky A, Sartorius N, Ernberg G, et al. Schizophrenia: manifestations, incidence and course in different cultures. A World Health Organization ten-country study. Psychol Med Monogr Suppl. 1992;20:1-97.

30. Fujita T. Trends of psychiatric in- and out-patients between 1973 to $1987-$ estimation based on the "patient survey" by the Ministry of Health and Welfare (report 1). Nihon Koshu Eisei Zasshi. 1991;38(3):233-245. Japanese.

31. Nakamura Y, Ojima T, Oki I, Tanihara S, Yanagawa H. Estimation of the future numbers of patients with mental disorders in Japan based on the results of National Patient Surveys. J Epidemiol. 1997;7(4):214-220.

32. Ichinowatari N, Tatsunuma T, Makiya H. Epidemiological study of old age mental disorders in the two rural areas of Japan. Jpn J Psychiatry Neurol. 1987;41(4):629-636.

33. Shingu K, Sato M, Miyoshi A. Psychiatric diagnosis in a Japanese university population - using DSM-III. J Am Coll Health. 1982;31(2): $67-72$.

34. Suzuki M, Morita H, Kamoshita S. Epidemiological survey of psychiatric disorders in Japanese school children. Part III: Prevalence of psychiatric disorders in junior high school children. Nihon Koshu Eisei Zasshi. 1990;37(12):991-1000. Japanese.

35. Ministry of Internal Affairs and Communications of Japan [webpage on the Internet]. [Vital statistics]. Tokyo: Ministry of Internal Affairs and Communications of Japan; 2009 [cited January 13, 2013]. Available from: http://www.e-stat.go.jp/SG1/estat/List.do?lid=000001054002. Accessed January 28, 2013. Japanese. 
36. Ministry of Health Labour and Welfare of Japan. Basic Survey on Wage Structure (Chingin Kozo Kihon Tokei Chosa). Tokyo: Ministry of Health, Labour and Welfare of Japan; 2008. Japanese.

37. National Police Agency of Japan. Statistics of Suicide in 2008 (Jisatsu no Gaiyo Shiryo). Tokyo: National Police Agency of Japan; 2009. Japanese.

38. Kaga M. The Analytical Research Related to Causes of Suicides Utilizing the Database of Psychological Autopsy. Tokyo: Ministry of Health, Labor and Welfare of Japan; 2009. Japanese.

39. Gold MR, Siegal JE, Russel LB, Weinstein MC, editors. CostEffectiveness in Health and Medicine. New York: Oxford University Press; 1996.

40. Briggs AH, Ades AE, Price MJ. Probabilistic sensitivity analysis for decision trees with multiple branches: use of the Dirichlet distribution in a Bayesian framework. Med Decis Making. 2003;23(4):341-350.

41. Claxton K, Sculpher M, McCabe C, et al. Probabilistic sensitivity analysis for NICE technology assessment: not an optional extra. Health Econ. 2005;14(4):339-347.
42. OECD [webpage on the Internet]. OCED health data 2012. Paris: The Organisation for Economic Co-operation and Development; 2011 [cited January 15, 2013]. Available from: http://www.oecd.org/document/60/0,3 746,en_2649_33929_2085200_1_1_1_1,00.html. Accessed January 28, 2013.

43. 2011 Census: Population and Household Estimates for England and Wales [webpage on the Internet]. Newport: Office for National Statistics; 2012 [cited January 18, 2013]. Available from: http://www.ons.gov.uk/ ons/rel/census/2011-census/population-and-household-estimates-forengland-and-wales/index.html. Accessed January 28, 2013.

44. [Transition of Purchasing Power Parity in OECD countries] [database on the Internet]. Tokyo: Statistics Bureau; 2011. Available from: http://www.stat.go.jp/data/sekai/03.htm. Accessed January 28, 2013. Japanese.

45. Sado M, Inagaki A, Yoshimura K, Koreki A, Fujisawa D. The Estimate of the Societal Cost Caused by Mental Illness (Seishin Shikkan no Shakaiteki Kosuto no Suikei). Tokyo: Ministry of Health, Labour and Welfare of Japan; 2011. Japanese.

\section{Publish your work in this journal}

Neuropsychiatric Disease and Treatment is an international, peerreviewed journal of clinical therapeutics and pharmacology focusing on concise rapid reporting of clinical or pre-clinical studies on a range of neuropsychiatric and neurological disorders. This journal is indexed on PubMed Central, the 'PsycINFO' database and CAS.
The manuscript management system is completely online and includes a very quick and fair peer-review system, which is all easy to use. Visit http://www.dovepress.com/testimonials.php to read real quotes from published authors.

Submit your manuscript here: http://www.dovepress.com/neuropsychiatric-disease-and-treatment-journal 